\title{
¿ES EL DERECHO UN SISTEMA DE MANDATOS? LA CRÍTICA DE HART A LA TEORÍA IMPERATIVISTA DEL DERECHO
}

\section{CARLOS ISLER SOTO*}

RESUMEN: Una de las doctrinas que se ha denominado tradicionalmente con el apelativo de "positivistas" es la que sostiene que el derecho es un sistema de leyes, y estas son mandatos de seres humanos. Tal doctrina, también conocida como "teoría imperativista del derecho", recibió su formulación clásica en la obra de John Austin. A mediados del siglo XX dicha doctrina recibió una durísima crítica por parte de otro autor positivista, H.L.A. Hart. En el presente trabajo, exponemos brevemente la doctrina de Austin y la demoledora crítica de Hart.

PALABRAS CLAVE: Mandato - ley - positivismo - Austin - Hart.

\section{¿IS THE BODY OF LAW A SYSTEM OF MANDATES? HART'S CRITICISM TO THE IMPERATIVE THEORY OF LAW}

ABSTRACT: One of the doctrines that has traditionally been named with the appellative of "positivist" is one that sustains that the Law is a system of laws, and the latter are mandates from human beings. Such doctrine, also known as "Imperative Theory of Law", was formulated in the work of John Austin. By mid 20 ${ }^{\text {th }}$ century said doctrine received a harsh criticism by another positivist author, H.L.A. Hart. This work briefly exposes Austin's doctrine and Hart's rough criticism.

KEY WORDS: Mandate - law - positivism - Austin - Hart.

Abogado. Magíster en Filosofía, Universidad de Chile. Profesor de Fundamentos Filosóficos del Derecho de la Pontificia Universidad Católica de Chile y de la Universidad Bernardo O'Higgins; profesor de Filosofía del Derecho en la Universidad Andrés Bello; y profesor de Derecho y Moral de la Universidad Diego Portales. Correo electrónico: carlos_isler@yahoo.com Fecha de recepción: 9 de noviembre de 2009.

Fecha de aprobación: 12 de enero de 2010. 


\section{INTRODUCCIÓN}

Herbert Hart se enfrentó, a mediados de la década del 50, a la pesada tarea de intentar reivindicar al entonces desprestigiado positivismo jurídico, al que se culpaba de la pasividad mostrada por tantos ante las leyes inicuas puestas por el régimen nacionalsocialista ${ }^{1}$. Para defender al positivismo, procederá a "purificarlo", desvinculando de él muchas de las tesis tradicionalmente adscritas a este, dejándolo reducido, en esencia, a la tesis de la negación de la conexión conceptual necesaria entre derecho y moral.

En uno de sus textos más conocidos, "El positivismo jurídico y la separación entre el derecho y la moral", Hart enuncia hasta cinco tesis distintas adscritas popularmente al positivismo jurídico, de las cuales procederá a descartar varias como integrantes del positivismo reformado que pretende defender.

Una de estas tesis tradicionalmente adscritas al positivismo, y que había causado el justo descrédito de este, era la comprensión de que "las leyes son mandatos de seres humanos" 2 , la que fue sostenida por ilustres representantes del positivismo anterior, como Bentham y Austin. Será una de aquellas a las que someterá a una fuerte crítica, la que expondremos en el presente trabajo, tras exponer sucintamente la teoría imperativista a la que critica.

1 El grado de descrédito que alcanzó el positivismo jurídico tras la Segunda Guerra Mundial se manifiesta en la célebre "conversión" de Gustav Radbruch al iusnaturalismo en la postguerra. Sobre el tema, son particularmente decidores sus escritos "Fünf Minuten Rechtsphilosophie" y "Gesetzliches Unrecht und übergesetzliches Recht", aparecidos en 1945 y 1946, respectivamente. Se encuentran incluidos como apéndices en RADBRUCH, Gustav (1932). Rechtsphilosophie, Heidelberg: C.F. Müller.

2 Las cinco tesis adscritas al positivismo tradicionalmente son las siguientes:

"(1) the contention that laws are commands of human beings...

(2) the contention that there is no necessary connection between law and morals or law as it is and it ought to be...

(3) the contention that the analysis (or study of the meaning) of legal concepts is (a) worth pursuing and (b) to be distinguished from historical inquiries into the causes or origins of laws, from sociological inquiries into the relation of law and other social phenomena, and from the criticism or appraisal of law whether in terms of morals, social aims, 'functions' or otherwise...

(4) the contention that a legal system is a 'closed logical system' in which correct legal decisions can be deduced by logical means from predetermined legal rules without reference to social aims, policies, moral standards...

(5) the contention that moral judgments cannot be established or defended, as statements of facts can, by rational argument, evidence, or proof ('noncognitivism' in ethics)...": HART, H.L.A (1958). "Positivism and the separation of Law and Morals", Harvard Law Review, vol 71, No 4, pp. 601-602, nota 25. Hart rechazará las tesis 1 y 4, y no se pronunciará sobre la 5 , sosteniendo que ella es extraña a la filosofía del derecho y pertenece a la filosofía moral. 


\section{1) LA TEORÍA IMPERATIVISTA DEL DERECHO DE JOHN AUSTIN}

\section{1) Propósito de la obra de Austin. Distinción entre los DISTINTOS ÍTEMES LLAMADOS “LEYES"}

El propósito que se planteó John Austin al dictar el curso que sería posteriormente publicado bajo el nombre de "El objeto de la jurisprudencia” fue, como ya lo indica tal nombre, delimitar cuál es el tema propio de la jurisprudencia o teoría general del derecho. Austin constata que se llama "leyes" a muchos ítemes distintos, desde aquel ítem que es un mandato de un soberano y que llamaríamos "ley positiva", hasta aquel otro ítem que es una oración enunciando una relación de causalidad necesaria entre dos fenómenos naturales, a la que llamaríamos ley científica (v. gr., la ley de gravedad), pasando por las llamadas leyes de urbanidad, del vestir, las leyes de Dios, etc. Habiendo tantos ítemes denominados con el mismo nombre, quiere determinar cuáles de ellos caen bajo el objeto de la jurisprudencia, y cuál es la esencia de tales ítemes, lo que todos ellos tienen en común.

Austin considera que las leyes propiamente tales son mandatos: "Las leyes propias, o propiamente llamadas, son mandatos; las leyes que no son mandatos son leyes impropias o impropiamente llamadas" 3 .

Las leyes propiamente tales pueden clasificarse en:

a) Leyes divinas.

b) Leyes positivas, las cuales "forman la materia adecuada de la jurisprudencia (jurisprudence) general y particular" ${ }^{4}$.

c) Parte de la moralidad positiva, esto es, las reglas morales que rigen en una sociedad determinada.

De las leyes propiamente tales deben diferenciarse otro tipo de ítemes también llamados "leyes", pero que no lo son en el sentido propio del término. Son las "leyes en sentido impropio", y tales son:

a) Parte de la moralidad positiva, consistentes en reglas impuestas por la opinión. Estas reglas son llamadas "ley” por analogía estrecha con las leyes propiamente tales.

b) Las leyes metafóricas, que son llamadas "ley" por analogía remota con las leyes positivas. "Tal es el caso cuando hablamos de las leyes observadas por los animales inferiores; de las leyes que regulan el crecimiento o deterioro de los vegetales; de las leyes que determinan los

Austin, John (1832). The Province of Jurisprudence Determined, Indianapolis: Hackett, p. 1. Austin (1832) 1 . 
movimientos de los cuerpos o masas inanimadas. Pues donde no hay inteligencia, o donde ésta se encuentra muy limitada para recibir el nombre de razón y, por ende, está muy limitada como para concebir el propósito de una ley, no existe la voluntad de la que la ley puede ocuparse, o a la cual el deber pueda incitar o refrenar" 5 .

Ahora bien: "una ley, en la acepción más general y comprehensiva en la cual el término es usado en su significación literal, puede decirse que es una regla establecida para la guía de un ente inteligente por un ente inteligente que tiene poder sobre él"6. Así entendido, con el término "ley" se significan las leyes divinas y las dadas por hombres a otros hombres.

Estas últimas, las leyes impuestas por hombres a otros hombres, pueden ser de dos tipos: en primer lugar, “algunas son establecidas por superiores politicos, soberano y sujeto: por personas que ejercen el gobierno supremo y subordinado en las naciones independientes o sociedades políticas independientes. El conjunto de reglas así establecidas, o algún conjunto que forme una porción de ese conjunto, es el objeto adecuado de la jurisprudencia, general y particular" 7 . Este conjunto de reglas es llamado "derecho" en sentido estricto o "derecho positivo", esto es, derecho existente por haber sido puesto.

En segundo lugar, "[algunas de las reglas o leyes que son establecidas por hombres para hombres] no son establecidas por superiores políticos, o no son establecidas por superiores políticos en esa capacidad o carácter" ${ }^{8}$. A estas reglas, junto con aquellas otras reglas establecidas "por la mera opinión, esto es, por las opiniones o sentimientos tenidos o experimentados por un conjunto indeterminado de hombres en relación a la conducta" (v. gr., la "ley del honor", las "leyes establecidas por la moda"), y que son ítemes impropiamente llamados leyes (por no ser mandatos), Austin las llama "moralidad positiva". "El nombre moralidad las separa de derecho positivo, al tiempo que el epíteto positiva las distingue de la ley de Dios"10. Por ende, la moralidad positiva está compuesta en parte por mandatos, y en parte por reglas distintas de mandatos.

¿Cuál es la esencia de una ley propiamente tal? Ante todo, "cada ley o regla (tomadas con la más amplia significación que pueda dársele al término propiamente) es un mandato. O, más bien, las leyes o reglas, propiamente así llamadas, son una especie de mandatos" 11.

Austin (1832) 12-13.

Austin (1832) 10.

Austin (1832) 11.

Austin (1832) 11.

Austin (1832) 12.

Austin (1832) 12.

Austin (1832) 13. Austin, según reconoce expresamente, depende fuertemente de Hobbes en su teoría imperativista. En efecto, este entendía la ley como un mandato: HobBes, 
Para Austin, el término "mandato" es "la clave de las ciencias de la jurisprudencia y moral"12. ¿Qué es un mandato? "Si expresas o intimas un deseo de que yo haga o me abstenga de hacer algún acto, y si me has de infligir un mal en caso de que yo no cumpla con tu deseo, la expresión o intimación de tu deseo es un mandato. Un mandato se distingue de otras significaciones de deseo no por el estilo con el cual es significado el deseo, sino por el poder y el propósito de la parte que manda de infligir un mal o sufrimiento en caso de que el deseo sea desatendido" 13 .

De lo anterior deduce Austin el significado de "deber": "siendo pasible de un mal por ti si no cumplo el deseo que significas, estoy ligado (bound) $\mathrm{u}$ obligado (obliged) por tu mandato, o estoy bajo un deber de obedecerlo"14. De ahí que "mandato y deber sean términos correlativos, estando el significado denotado por cada uno implicado o supuesto por el otro" 15 .

Ahora bien: "el mal que probablemente ocurrirá en caso de que un mandato sea desobedecido o (para usar una expresión equivalente) de que un deber sea infringido, es frecuentemente llamado una sanción, o la imposición de la obediencia. O (variando la frase) el mandato o deber se dice que es sancionado o impuesto por la posibilidad de incurrir en el mal" 16 . Es importante que, para que exista mandato, debe haber posibilidad de incurrir en la sanción en caso de desobediencia. Cuán grande sea esa posibilidad, es irrelevante: "donde existe la menor posibilidad de incurrir en el menor daño, la expresión del deseo equivale a un mandato y, consiguientemente, impone un deber" 17.

Austin excluye como sanciones o imposiciones de los mandatos a los premios, a los que Locke y Bentham incluían dentro de tales imposiciones. A tales celebrados autores refuta Austin expresando que "los premios son, indiscutidamente, motivos para cumplir con los deseos de otros. Pero

Thomas (1651). Leviathan, Indianapolis: Hackett, c. XXVI, p. 173: “...it is manifest that law in general is not counsel, but command; nor a command of any man to any man, but only of him whose command is addressed to one formerly obliged to obey him. And as for civil law, it addeth only the name of the person commanding, which is persona civitatis, the person of the commonwealth". También p. 177: “... the law is a command, and a command consisteth in declaration or manifestation of the will of him that commandeth (by voice, writing, or some other sufficient argument of the same)".

12 Austin (1832) 13.

13 Austin (1832) 14. Austin se refiere aquí al conocido fenómeno de que puede expresarse un mandato no solo con oraciones en imperativo, sino también con oraciones en indicativo. Incluso puede darse una orden bajo la forma de una petición. Austin se refiere a tal caso, recordando la cita de Tácito: "Preces erant, sed quibus contradici non posset".

14 Austin (1832) 14.

15 Austin (1832) 15. Por ende, hay una relación de implicación recíproca entre mandato y deber.

16 Austin (1832) 15. Por ende, hay una relación de implicación recírpoca entre mandato y sanción posible y deber y sanción posible. Austin (1832) 16. 
hablar de mandatos y deberes como sancionados o impuestos por premios, o hablar de premios como obligando o constriñendo a la obediencia, es con certeza una desviación muy grande respecto del significado establecido de los términos" ${ }^{18}$. ¿Qué pasa si una ley establece un premio en caso de la realización de una actuación? En tal caso, "se confiere un derecho eventual, y no se impone una obligación, sobre aquellos que han de actuar de la manera adecuada, y la parte imperativa de la ley tiene como destinatarios o se dirige a la parte a la que requiere que otorgue el premio" ${ }^{19}$. Es decir, si una ley impone un derecho, impone una obligación correlativa a otra parte, la que se encuentra obligada por tal ley.

En síntesis, "estoy determinado o inclinado a cumplir con el deseo de otro por el miedo de inconveniencia o mal. También estoy determinado o inclinado a cumplir con el deseo de otro por la esperanza de provecho o bien. Pero estoy ligado u obligado a cumplir solo por la posibilidad de incurrir en mal. Los deberes son sancionados o impuestos solo por el mal condicional. Es el poder y el propósito de infligir mal eventual, y no el poder y el propósito de impartir bien eventual, lo que le da a la expresión de un deseo el nombre de un mandato" 20 .

Ahora bien: los mandatos son de dos especies: las leyes o reglas, y una segunda categoría que Austin sostiene ser hasta el momento innominada, y a la que llamará "mandatos ocasionales o particulares". La diferencia entre ambos estriba en que los primeros obligan "generalmente a

Austin (1832) 16.

Austin (1832) 17.

Austin (1832) 17. Conviene entender bien lo que Austin expresa aquí: él está simplemente haciendo un análisis del lenguaje ordinario, y constatando que no tendemos a hablar de mandatos en los casos de expresiones de deseos que no llevan aparejadas la amenaza de una sanción en caso de desobediencia. Está simplemente dando cuenta de un hecho lingüístico, de cómo se utilizan ciertos términos en la Inglaterra del siglo XIX.

No está, en cambio, tratando sobre cómo es la naturaleza de las cosas, más allá de cómo hablemos de ellas, y expresando que solo hay deber donde existe un mandato acompañado por la amenaza de la imposición de un mal en caso de desobediencia, que el deber, en consecuencia, emana de la posibilidad de incurrir en un mal, y que no hay deber alguno en el caso de que el motivo para actuar sea un bien, que no hay deber de alcanzar el bien. En síntesis: que hay deber de evitar el mal, pero no hay deber de alcanzar el bien. En tal caso, Austin se estaría oponiendo a la filosofía moral clásica, que consideraba que el concepto de deber es ininteligible sin el de bien, que deriva de este. Recuérdese que el primer principio de la ley natural en Santo Tomás es "bonum est faciendum et prosequendum et malum est vitandum": "se ha de hacer y perseguir el bien, y evitar el mal". Existe un deber, una obligación, de perseguir el bien, y ello por cuanto el fundamento de la ética y filosofía política clásica es la noción de bien, no la de mal. Recién con Hobbes comienza a ser el mal la noción sobre la que se funda la filosofía de las cosas humanas. Que Austin simplemente está haciendo un análisis del lenguaje ordinario de su tiempo, queda claro por otras expresiones posteriores ("if we put reward into the import of the term sanction, we must engage in a toilsome struggle with the current or ordinary speech": Austin (1832) 17), y además si se tiene en cuenta que Austin es un utilitarista, y es sabido que los utilitaristas sostienen que existe un deber moral de alcanzar ciertos bienes, como la felicidad entendida como presencia de placer y ausencia de dolor. 
actos o abstenciones de una clase”, mientras que los segundos obligan “a un acto o abstención específicos, o a actos o abstenciones que determina especificamente o individualmente" 21 . El ejemplo más claro de mandatos ocasionales serían, normalmente, los mandatos judiciales. Austin reconoce que, en caso de que un mandato ocasional fuese dictado por un parlamento o por el soberano, "en tanto se encuentran bajo la forma de una ley... sería probablemente llamada ley" 22 .

Austin expone que Blackstone y otros autores han trazado la distinción entre tipos de mandatos en atención a criterios distintos: para ellos, un mandato es una ley si obliga a una generalidad de personas o a un grupo de personas de una clase, y es ocasional si obliga a un individuo o a personas determinadas individualmente. Austin, en cambio, no considera que sea de la esencia de una ley obligar a una clase de personas, aunque en la mayor parte de los casos tal hará, porque "elaborar un sistema de deberes para cada individuo de la comunidad sería simplemente imposible, y si fuese posible, sería completamente inútil. La mayoría de las leyes establecidas por los superiores políticos son, en consecuencia, generales en un doble modo: en cuanto prescriben y prohíben generalmente actos de tipos o clases, y en cuanto vinculan a la comunidad entera o, al menos, clases enteras de sus miembros"23.

\section{2) SUPERIORIDAD Y MANDATOS}

Los mandatos son dictados por superiores a inferiores. Ambos términos son correlativos. Superioridad, para Austin, significa "potestad (might): el poder (power) de afectar a otros con mal o sufrimiento, y de forzarlos, por medio del miedo a tal mal, a ajustar su conducta a los deseos propios.

Por ejemplo, Dios es enfáticamente el superior del hombre. Pues su poder de afectarnos con sufrimiento y de forzarnos a cumplir con su voluntad es ilimitado e irresistible.

Hasta cierto punto, el individuo o grupo soberano es el superior del súbdito o ciudadano; el amo, del esclavo o siervo; el padre, del hijo.

En breve, cualquiera que puede obligar a otro a cumplir con sus deseos, es el superior de tal otro, tanto como su capacidad alcance. La parte sobre la que pende el mal inminente es, con la misma extensión, el inferior" 24 . Por ende, el término "superioridad" está implicado por el de "mandato".

Dios es superior absoluto. En cambio, las relaciones de superioridad

Austin (1832) 19.

Austin (1832) 20.

Austin (1832) 23.

Austin (1832) 24-25. 
e inferioridad entre los entes humanos no tienen tal carácter absoluto: “en todos o en la mayoría de los casos de superioridad humana, la relación de superior e inferior, y la relación de inferior y superior, son recíprocas. $\mathrm{O}$, (cambiando la expresión), la parte que es superior bajo cierto aspecto es la inferior vista desde otro" 25 . Así, por ejemplo, un gobernante es superior respecto de sus súbditos, "pero los gobernados, colectivamente o en masa, son también superiores al monarca, que es controlado en el abuso de su potestad por el miedo a excitar su ira, y de despertar al estado de resistencia activa el poder que duerme en la multitud" 26 .

Austin sostiene que existen ítemes impropiamente llamados "leyes" -por no ser mandatos- y que, sin embargo, de forma excepcional entran dentro del objeto de la jurisprudencia. Tales son:

a) lo que hoy llamamos "leyes interpretativas": "decretos (acts) de parte de las legislaturas para explicar la ley positiva... En tanto no producen cambio alguno en los deberes actuales de los gobernados, sino que simplemente declaran cuáles son esos deberes, son propiamente actos de interpretación por la autoridad legislativa" 27.

b) las leyes derogatorias de otras leyes, que no son mandatos, sino revocaciones de mandatos. "Remotamente o indirectamente, sin embargo, las leyes permisivas son comúnmente o siempre imperativas. Pues las partes liberadas de deberes son restablecidas en libertades o derechos, y los deberes correlativos a aquellos derechos son, en consecuencia, creados o revividos" 28 .

c) Leyes imperfectas, esto es, leyes sin sanción y, por ende, no vinculantes. "Aunque el autor de una ley imperfecta significa un deseo, no manifiesta propósito alguno de forzar el cumplimiento del deseo" 29 $y$, por ende, tal ley imperfecta no es un mandato.

Austin se enfrenta, asimismo, a presuntas excepciones a su teoría de que toda ley es un mandato que impone un deber. En primer lugar, las leyes que solo crean derechos. Austin niega que existan tales leyes: toda ley que crea derechos, crea siempre deberes correlativos. Puede existir una ley que solo cree deberes, no correspondientes a derechos correlativos, y tales deberes serían "absolutos". Sin embargo, no puede existir una ley que solo cree derechos: si crea derechos, crea deberes correlativos, que son llamados deberes "relativos" 30 .

Austin (1832) 25.

Austin (1832) 25.

Austin (1832) 26.

Austin (1832) 27.

Austin (1832) 28.

Por ende los deberes son anteriores a los derechos. 
El segundo caso es el de las llamadas "leyes consuetudinarias" (customary laws). Aquí se le plantea a Austin un problema serio: es obvio que los jueces del Common Law aplican reglas consuetudinarias. Ahora bien: tales reglas imponen deberes y, sin embargo no parecen ser mandatos, por cuanto no han sido mandados por nadie. Blackstone y otros, así como los juristas alemanes de la Escuela Histórica, consideraban que aquí existía un derecho no proveniente del Estado, sino de la sociedad. Como Austin reconoce, "por muchos de los admiradores de las leyes consuetudinarias (y, especialmente, de sus admiradores alemanes), son consideradas como obligando jurídicamente (con independencia del soberano o del Estado) porque los ciudadanos o súbditos las han observado o cumplido. Conforme a esta opinión, no son las creaturas del soberano o del Estado, aunque el soberano o el Estado pueda abolirlas a voluntad"31. Parecería que la costumbre, como fuente del derecho, surgiese no de los superiores políticos sino de la misma comunidad gobernada.

Pues bien: para Austin no es así: las leyes consuetudinarias obligan porque el soberano así lo ha ordenado: "en su origen, una costumbre es una regla de conducta que los gobernados observan espontáneamente, o no cumpliendo con una ley establecida por un superior político. La costumbre es transformada en ley positiva cuando es adoptada como tal por los tribunales de justicia, y cuando las decisiones judiciales creadas sobre ellas son impuestas por el poder del Estado"32. Antes de ser aplicadas por los tribunales, tales costumbres son prejurídicas. Adquieren el carácter de costumbres jurídicas al ser aplicadas por los tribunales, porque entonces pasan a ser ordenadas por el soberano. Sucede que el juez es, por subordinado al soberano, un ministro de este, y su poder deriva de este, es una porción delegada del poder soberano. Por ende, "las reglas que crea derivan su fuerza legal de la autoridad dada por el Estado, autoridad que el Estado puede conferir expresamente, pero que comúmnente imparte por medio de la aquiescencia. Pues, desde que el Estado puede revertir las reglas que crea y, con todo, le permite imponerlas por el poder de la comunidad política, la voluntad de su soberano de 'que sus reglas sean derecho' se manifiesta claramente por su conducta, aunque no por su declaración expresa"33. El soberano, pudiendo revertir la aplicación que el juez hace de la costumbre prejurídica, no lo hace y muestra así su aquiescencia, muestra su satisfacción. En consecuencia, existe un mandato tácito del soberano al juez para que aplique la costumbre. Sucede que "un mandato, como otras significaciones de deseo, es expreso o tácito. Si el deseo es significado por palabras (escritas o habladas), el mandato es expreso. Si

Austin (1832) 30.

Austin (1832) 31.

Austin (1832) 32. 
el mandato es significado por la conducta (o por cualesquiera signos de deseo que no son palabras), el mandato es tácito.

Ahora, cuando las costumbres son transformadas en reglas jurídicas por decisiones de los jueces súbditos, las reglas jurídicas que emergen de las costumbres son mandatos tácitos de la legislatura soberana. El Estado, que puede abolirlas, permite a sus ministros imponerlas $y$, por consiguiente, significa su satisfacción" 34 .

\section{3) LAS LEYES POSITIVAS. SOCIEDAD POLÍTICA INDEPENDIENTE}

Las leyes positivas son la materia adecuada de la jurisprudencia. Ahora bien: las leyes positivas se distinguen de las divinas por el superior de quien proceden: las segundas proceden de Dios, las primeras del soberano de una sociedad política independiente: ley es el género, ley positiva la especie, y "la diferencia esencial de una ley positiva (o la diferencia que la distingue de una ley que no es positiva) puede ser expresada así. Toda ley positiva, o toda ley simple y estrictamente llamada tal, es establecida por una persona soberana, o un cuerpo soberano de personas, para un miembro o miembros de la sociedad política independiente en la cual tal persona o cuerpo es soberano o supremo" 35 .

Por consiguiente, Austin procederá a explicar los significados de las nociones de "soberano" y "sociedad política independiente".

Ahora bien: "la superioridad que es llamada soberanía, y la sociedad política independiente que la soberanía implica, se distingue de otra superioridad, y de otra sociedad, por los siguientes rasgos o caracteres: 1. El grueso de la sociedad dada tiene un hábito de obediencia o sumisión a un superior común y determinado, sea que el superior común sea una cierta persona individual, o un cierto cuerpo o agregado de personas individuales. 2. Aquel cierto individuo, o aquel cierto cuerpo de individuo, no tiene un hábito de obediencia respecto a un superior humano determinado" 36 . La sociedad política independiente se caracteriza así por dos rasgos, uno positivo o uno negativo. Si falta el rasgo positivo, la sociedad en cuestión se encuentra en estado de naturaleza, o bien dividida en dos o más sociedades políticas independientes (v. gr. el caso de una guerra civil).

Una sociedad política independiente está así compuesta por el soberano, que vive en estado de independencia, y los súbditos, que viven en estado de sujeción. De ahí que no sea la sociedad quien es independiente propiamente, sino solo aquella parte de ella que es soberana.

Austin (1832) 32.

Austin (1832) 193.

Austin (1832) 194. 
Asimismo, se requiere, para que exista una sociedad política independiente, que esta tenga un número mínimo de miembros: "una sociedad independiente dada, cuyo número pueda ser llamado ínfimo, es comúnmente estimada una sociedad natural, no politica, aunque la generalidad de sus miembros sean habitualmente obedientes o sumisos a un cierto superior común.

(...) Para que una sociedad independiente pueda formar una sociedad política, no debe caer bajo un número que pueda ser llamado considerable.

El número más bajo posible que satisfará tal condición vaga no puede ser fijado con precisión" 37 , aunque debe exceder al menos de unos cuantos cientos.

\section{4) SOBERANÍA}

El soberano es quien recibe obediencia habitual del grueso de la población, y a su vez no presta obediencia habitual a nadie. Para Austin, las formas supremas de gobierno son dos: monarquía y aristocracia, según sea que el soberano sea unipersonal o un grupo de personas. En el caso del soberano aristocrático, compuesto de varios miembros, estos pueden compartir el poder de múltiples modos. De ahí que existan infinitas formas de aristocracia (v. gr. un triunvirato, una junta de gobierno, etc.). Según Austin, en las sociedades democráticas el soberano aristocrático está compuesto por el conjunto de los electores.

Asimismo, el soberano puede ejercer su poder directamente, o bien por medio de delegados que lo representan (v. gr. un intendente, un virrey).

Es particularmente importante lo siguiente: el soberano no está sujeto a ninguna limitación legal. Ello, por cuanto "toda ley es establecida, directa o indirectamente, por una persona o cuerpo soberano a una o más personas de la sociedad política independiente de la cual tal persona o cuerpo es soberano o supremo"38; la ley es puesta por el soberano para aquellos miembros de la sociedad que se encuentran en estado de sujeción. Solo estos quedan obligados por las leyes: "se sigue de la diferencia esencial de una ley positiva, y de la naturaleza de la soberanía y de la sociedad política independiente, que el poder de un monarca propiamente llamado, o el poder de un miembro soberano en su capacidad colegiada y soberana, es incapaz de limitación jurídica. Un monarca o miembro soberano vinculado por un deber legal estaría sujeto a un soberano más alto o superior, esto es, un monarca o miembro soberano 
vinculado por un deber legal sería soberano y no soberano. Poder supremo limitado por el derecho positivo es una simple contradicción en los términos" 39 .

Más aún: la misma Constitución tampoco obliga jurídicamente al soberano. Sucede que la Constitución es, para Austin, parte de la moralidad positiva de la sociedad de la que se trate: "contra un monarca propiamente así llamado, o contra un cuerpo soberano en su capacidad colegiada y soberana, el derecho constitucional es meramente moralidad positiva, o es impuesto meramente por sanciones morales, aunque... puede llegar a ser derecho positivo, o puede ser impuesto por sanciones legales, contra los miembros del cuerpo considerados individualmente... Consecuentemente, aunque el acto de un soberano que viola el derecho constitucional puede ser llamado con propiedad inconstitucional, no es infracción de alguna ley llamado así simple y estrictamente, y no puede ser llamado con propiedad ilegal' 40 . La razón es sencilla: ¿quién puede imponer al soberano el cumplimiento del derecho constitucional? La respuesta es clara: nadie. Por ende, se trata de mera moralidad positiva. El soberano ni tiene limitación jurídica alguna, aunque esté limitado por la moral positiva y por la ley de Dios. Esta última limitación no es jurídica, porque la ley divina no es derecho positivo.

\section{2) LA CRÍTICA DE HART AL MODELO DEL DERECHO COMO UN SISTE- MA DE MANDATOS}

H.L.A. Hart, a mediados del siglo XX, intenta desarrollar una teoría descriptiva del derecho. Para Hart, teoría descriptiva es sinónimo de teoría positivista: si lo que se quiere es describir adecuadamente el objeto de estudio que denominamos "derecho", debemos partir por reconocer que no existe conexión necesaria entre el derecho y la moral. Simplemente, hay sistemas jurídicos injustos. Hart cita el de la Alemania nazi y la Sudáfrica de su tiempo.

\footnotetext{
39 Austin (1832) 254; Новвеs (1651) 174: "The sovereign of a commonwealth, be it an assembly or one man, is not subject to the civil laws. For having power to make and repeal laws, he may, when he pleaseth, free himself from that subjection by repealing those laws that trouble him and making of new; and consequently, he was free before. For he is free that can be free when he will; nor is it possible for any person to be bound to himself, because he that can bind can release; and therefore, he that is bound to himself only is not bound".

$40 \quad$ Austin (1832) 259.
} 
La teoría de la no conexión conceptual necesaria entre derecho y moral fue enunciada por vez primera por Austin, y Hart reconoce en esto su deuda con el jurista decimonónico. Así, en cierta medida, su obra se encuentra en continuidad con la de Austin.

Sin embargo, Hart rechazará una de las doctrinas más caras a Austin y a otros positivistas anteriores a él, como Bentham: que el derecho sea un sistema de mandatos.

Como se vio anteriormente, para John Austin el derecho es un conjunto de mandatos emanados de un superior llamado soberano vinculando a los súbditos de este soberano.

Pues bien: Hart sostendrá que la teoría imperativa del derecho no puede dar cuenta de ciertas características notorias del sistema jurídico. Sucede lo siguiente: las leyes-mandatos de Austin a lo más se asemejan a cierto tipo de leyes, aquellas que imponen obligaciones. El caso más típico sería el de las normas del derecho penal, que efectivamente imponen la realización de acciones o abstenciones bajo la amenaza de una sanción.

Sin embargo, frente a este tipo de normas que imponen obligaciones, existen otras muy distintas, que no imponen obligaciones, sino que otorgan facultades, públicas o privadas, y que no pueden, so pena de ser deformadas, ser reducidas a mandatos. Un ejemplo sería la ley de matrimonio civil, que no expresa mandato alguno, sino que provee a las partes de un instrumento para cumplir sus fines: el casarse.

Hart enuncia tres tipos de objeciones fundamentales al modelo del derecho como un sistema de mandatos imponiendo obligaciones bajo amenaza de una sanción. Tales objeciones se basan en el contenido de las leyes, en su rango de aplicación, y en su modo de origen.

\section{3) OBJECIONES BASADAS EN EL CONTENIDO DE LAS LEYES}

Hart reconoce que las normas del derecho penal, lo mismo que las propias del derecho de daños, se asemejan enormemente a mandatos acompańados por la amenaza de una sanción en caso de desobediencia. La ley que castiga el hurto ordena abstenerse de apropiarse de cosa mueble ajena con ánimo de lucro y sin la voluntad de su dueño, amenazando al potencial infractor con una sanción en caso de incumplimiento. Hasta ahí, el modelo de Austin parece dar cuenta adecuadamente de la naturaleza del derecho.

Sin embargo, "existen importantes clases de leyes en las cuales esta analogía con órdenes respaldadas por amenazas falla completamente, desde que cumplen una función social muy distinta. Las reglas jurídicas que determinan los modos cómo se hacen contratos o testamentos o matrimonios válidos no exigen de las personas que actúen de modos determinados lo deseen o no. Tales leyes no imponen deberes u obligaciones. Más bien, proveen a los individuos con medios (facilities) para realizar sus deseos, al 
conferirles poderes jurídicos para crear, por ciertos procedimientos específicos y sujetos a ciertas condiciones, estructuras de derechos y deberes dentro del marco coercitivo del derecho" 41 .

Asimismo, otro tipo de leyes que no imponen obligaciones, sino que confieren potestades, son aquellas que confieren potestades públicas para crear, aplicar y ejecutar las leyes existentes. Por ejemplo, las normas que especifican quiénes y de qué modo podrán crear nuevas leyes, tales normas no imponen a sus destinatarios, los parlamentarios, obligación alguna.

Y estas reglas no pueden reducirse a reglas que imponen obligaciones: "en algunos casos sería grotesco asimilar estos dos amplios tipos de reglas. Si una medida ante un cuerpo legislativo obtiene la requerida mayoría de votos y es, consiguientementa, aprobada, los votantes en favor de la medida no han 'obedecido' la ley que requería una decisión mayoritaria, ni la han obedecido o desobedecido quienes votaron contra ella; lo mismo es, por supuesto, correcto, si la medida no alcanza a obtener la mayoría requerida y, por ende, no es aprobada" 42 .

Si solo existiesen las reglas que imponen obligaciones, y careciésemos de estas reglas que otorgan potestades, "careceríamos de algunos de los conceptos más familiares de la vida social, desde que estos presuponen la existencia de tales reglas" 43 . Por ejemplo, los conceptos de matrimonio, contrato, testamento, tribunal, legislación, juez.

No todas las reglas son mandatos. Sin embargo, ¡existe algo que tengan en común las reglas que imponen obligaciones, y aquellas que confieren potestades públicas o privadas? Sí: "tanto la regla que confiere potestades relativa a la realización de un testamento y la regla del derecho penal que prohíbe el asalto bajo pena constituyen estándares por los cuales acciones particulares pueden ser críticamente apreciadas" ${ }^{44}$. El derecho no está compuesto de mandatos: está compuesto de estándares para la apreciación crítica de acciones humanas. A tales estándares Hart llamará "reglas" (rules). El derecho no es un sistema de mandatos, es un sistema de reglas.

\section{4) OBJECIONES BASADAS EN EL RANGO DE APLICACIÓN DE LAS NORMAS}

Si el derecho es un sistema de mandatos respaldados por amenazas, entonces no pueden tales mandatos obligar a sus autores. La idea de mandato implica el que se ordene a otro. Es absurdo pensar que alguien se mande a sí mismo, amenazándose con provocarse un daño en caso de incumplimiento.

Hart, H.L.A. (1961). The Concept of Law, New York: Oxford University Press, p. 28.

Hart (1961) 31-32.

Hart 32.

HART 33. 
De acuerdo a esto, sería esencial al derecho que exista una persona o grupo de personas, el "soberano" en Austin, que pone el derecho y por definición está fuera y no vinculado por él. Tal sostiene, precisamente, Austin: el soberano es jurídicamente ilimitado.

Sin embargo, sostiene Hart, "la legislación, en tanto distinta del ordenar a otros a hacer cosas bajo amenazas, puede perfectamente tener tal fuerza autovinculante. No hay nada esencialmente referido a otro en ella" ${ }^{45}$. Es muy probable que la legislación en una monarquía absoluta no obligue al monarca. Sin embargo, en los estados democráticos hay leyes que obligan a sus creadores. Por ende no son mandatos.

Podría, con todo, Austin retrucar que tales leyes obligan a los legisladores en su calidad de individuos privados, no en cuanto miembros del cuerpo soberano. La respuesta de Hart es sencilla: "no hay nada objetable en esta forma de expresión, pero la noción de diferentes capacidades... es inteligible solo en términos de reglas de derecho que confieren potestades que no pueden ser reducidas a reglas coercitivas" 46 .

Por ende, y contra la teoría imperativa, "lo que mayormente se necesita como correctivo al modelo de órdenes coercitivas o reglas, es una concepción nueva de la legislación como la introducción o modificación de estándares generales de comportamiento a ser seguidos por la sociedad en general" 47 .

\section{5) OBJECIONES BASADAS EN EL MODO DE ORIGEN DE LAS NORMAS}

Según el modelo del derecho como un sistema de mandatos, cada ley tendría que ser producto de un acto deliberado de creación jurídica: donde hay ley existe necesariamente un deseo del soberano que se ha manifestado expresa o tácitamente.

Pero, objeta Hart, existen normas en nuestros sistemas jurídicos que manifiestamente no proceden de un acto deliberado de creación jurídica. Tal es el caso de la costumbre. Nadie la ha mandado.

Se ha de recordar que Austin enfrentó este problema, y lo resuelve mediante la noción de mandato tácito del soberano.

Pues bien: para Hart, tal noción es engañosa, por cuanto no se puede interpretar la inacción de un superior respecto de la actuación de un inferior como signo de su beneplácito. Puede suceder que el superior ignore la actuación del inferior, o bien que, conociéndola, no se complazca en ella pero no interfiera con ella por simple tolerancia y no por beneplácito.

\footnotetext{
45 HART 42.

HART 43.

HART 44
} 
Hart pone el siguiente ejemplo: imaginemos que un sargento está "aporreando" a un grupo de soldados. El general lo sabe y, sin embargo, no interviene. ¿Existe aquí una orden tácita del general en orden a que haga sudar a los soldados? No necesariamente: puede suceder que el general no intervenga por desidia, o bien, considerando que el castigo es excesivo y no gustándole, no intervenga con el fin de no desautorizar al sargento. En ninguno de tales casos puede entenderse que hay una "orden tácita” del general al sargento en orden a castigar a los soldados.

Si ya resultaba dudosa la interpretación de la inacción del general, en el caso mencionado, como una orden tácita al sargento, más dudosa resulta aún la atribución de tal orden tácita al soberano: "la mayor objeción al uso de la idea de expresiones tácitas de la voluntad del soberano para explicar el estatuto jurídico de la costumbre es que, en cualquier Estado moderno, es difícilmente posible adscribir tal conocimiento, consideración y decisión de no interferir al 'soberano', sea que identifiquemos al soberano con la legislatura suprema o con el electorado" 48 .

\section{CONCLUSIONES}

La crítica de Hart a la teoría imperativista es devastadora. Cualquier intento de concebir al derecho como un sistema de mandatos tiene que hacerse cargo de tal crítica. Lo verdaderamente interesante de la crítica de Hart es que dará paso a su conocida teoría del derecho como unión de dos tipos de reglas, las primarias y secundarias, siendo ambas estándares para la apreciación crítica de acciones humanas y proveyendo a los sujetos de razones para actuar. Una vez captado que las normas jurídicas son razones para actuar, el positivismo estará listo para ser superado, primero en la concepción servicial del derecho de Raz, y luego en el iusnaturalismo de Finnis. Hart, que quería ser positivista, con su acertada crítica a sus antecesores positivistas, prepara el camino para la superación del positivismo.

\section{BIBLIOGRAFÍA}

- Austin, John (1832). The Province of Jurisprudence Determined, Indianapolis: Hackett.

- Hart, H.L.A. (1958). "Positivism and the separation of Law and Morals", Harvard Law Review, vol. 71, No 4.

ty Press.

(1961). The Concept of Law, New York: Oxford Universi-

- Hobbes, Thomas (1651). Leviathan, Indianapolis: Hackett.

- Radbruch, Gustav (1932). Rechtsphilosophie, Heidelberg: C.F. Müller.

48 HART 48. 